\title{
The Banking System and the Derivatives: The State of the Art and the Management Mechanisms
}

\author{
Mostéfaoui Sofiane, Yousfat Ali \\ Department of Management Sciences, University of Adrar, Adrar, Algeria
}

Email address:

dr.yousfatali@gmail.com (Y. Ali)

${ }^{*}$ Corresponding author

\section{To cite this article:}

Mostéfaoui Sofiane, Yousfat Ali. The Banking System and the Derivatives: The State of the Art and the Management Mechanisms. International Journal of Economics, Finance and Management Sciences. Vol. 4, No. 5, 2016, pp. 309-313. doi: $10.11648 /$ j.ijefm.20160405.22

Received: January 3, 2016; Accepted: April 5, 2016; Published: October 27, 2016

\begin{abstract}
The financial transactions witnessed an explosion and huge dealings with financial derivatives. The sense of these assets comes from the dependence of their values on the principal ones (the original asset: bond, equity, exchange rate...). The objective behind the emergence and the wide uses of them is to hedge the financial securities against risks and reduce the volatility of their revenues. This paper attempts to shed light on the impact of the financial derivatives on the safety and soundness of the banking system by analyzing the determinants of this impact and the sensitiveness of the banking system to risks associated by the usage of the financial derivatives.
\end{abstract}

Keywords: Financial Derivatives, Risks, Banking System

\section{Introduction}

Derivatives are defined as contracts of values derived from the level and magnitude of the notional securities: exchange rate, bond, equity, price (Gorton\& Rosen, 1995). Derivatives are different according to the specificities of the original financial security and its level of business transaction. For instance, the literature cited the following ones: options, swaps, futures and forwards. The objective of the adoption of this channel of financial industry is to hedge, transfer risks and reduces the inherent volatility of the financial assets. In this context, Julian Walmsley (Michael Carter, 1989) noted that:

Risk transferring innovations are new instruments or techniques that allow investors or traders to transfer the price or credit risks in financial positions.... They include interest-rate and foreign-exchange futures and options, currency and interest rate swaps, and a host of other futures and options contracts enabling the hedging of various price risks. Probably the two biggest factors in developing these markets were the breakdown of fixed exchange rates, and the emergence of floating currencies in the mid- 1970 s, coupled with the adoption by the Federal Reserve of its New Economic Policy in October 1979, which led to unprecedented in stability of interest rate.

The deeper insight of the observation gives rise to ask questions about the ability of the banking system to evaluate fairly the risks of their operations even if there are hedged by these instruments. Hence, the focus on the factors conducting the occurrence and the unmatched risks is of paramount importance in order to conceive the suitable strategy of hedging. The framework is about assessing the internal and the external aspects of the economic transaction requirements (internal: type of the principal security, maturity, and the psychology of the financial agent - external: prices and conditions of the market). Regardless of the perceived benefits of these instruments with an appropriate strategy adoption, another controversy may state that the wide scope of the derivatives is not due to the sophistication and the soundness of the banking system but stems undeniably from its inability to secure the financial assets as an institution (the organizational analysis of the banking institutions) and its inefficiency to perform reasonably the financial intermediation process (the economical analysis of the banking institutions).

Distant from these clashing views, other factors influence the smoothing of the financial derivatives in favor of the intents of the banking institution. These factors are: the level 
of speculation, the sensitiveness towards risks and the social development of the financial system.

\section{The Level of Speculation}

The magnitude of speculation of the financial agents manipulates the ways by which the derivatives assume risks. The correlation between the two is positive as the increase of the financial agents' speculation and taking high risks positions lead to high probability of risk default even if the derivative is used strategically (the story of S\&P500 and the mortgages in 1989). If $\mathrm{S}$ denotes speculation and $\mathrm{V}$ is the vulnerability of the banking institution drawn from the increasing risk taking behavior, we state the positive relationship along the period of the transaction as: $(\delta V / \delta S)>0$ and the suitable financial strategy in this case is to minimize the vulnerability of the banking institution via the efficient and reasonable uses of the derivatives:

$\operatorname{Min}\left(V_{t D}\right) / t$ : time horizon, D: derivatives

Under the constraint of the speculative behaviors $\mathrm{S}$, and the proper strategy is shaped by these two borders, and when a bank is judged as a good strategically position taker, this means implicitly that the derivatives had a positive strategy consequence to overcome the turbulence comes from the herd and crazy speculators.

In addition, the level of speculation considered as a determinant of the impact between the banking institution and the derivatives is a fertile soil of raising questions about the sensitiveness of the vulnerability or the soundness of the banking institution to the wide or narrow uses of the derivatives: to what extent it is considered as strategically useful for banks to use derivatives as a mean to lessen the negative impacts of the mad speculators?

This issue shows up the importance of the elasticity notion as the latter measures not just in terms of quantities but in qualities also the degree of variability between two interdependent factors:

$$
e(V, D)=\frac{d V / V}{d D / D}
$$

This elasticity must be positive if the banking institution wants to use the derivative as a strategic mean, and the optimum point is that which realizes the target of the bank in terms of profitability, management (ensuring high level of micro-governance and gaining a fair market share).

\section{The Sensitiveness Towards Risks}

As the financial derivatives are coppers of risks, it is necessary to analyze the width of this copper and its ability to support much risks emanating from markets and instruments. Markets are origins of unexpected behaviors (speculation) and facts (prices instability). To sustain the rational conduct of these economic entities vis - $a$-vis the factors cited above, it should maintain a board inside the bank that takes into account the evolving trend of the exogenous factor (prices of the assets) and the inside one which is about the corporate efficiency of the bank to deal with the amount, quality and the uncertainty of prices. These two factors are important to assert how far the derivative is practical to maintain the good organization of banks.

Consider the market prices of the original instruments by IP, so the bank intends to decrease the volatility of these prices not by an exit strategy but by an offensive one via the channel of the derivatives. The practical and technical approach available to the bankers is to search for the focal point that links the three targets simultaneously: the bank profitability, the bank management, the bank market share as it is shown by the diagram below:

\section{Bank management (Risk versus Target)}
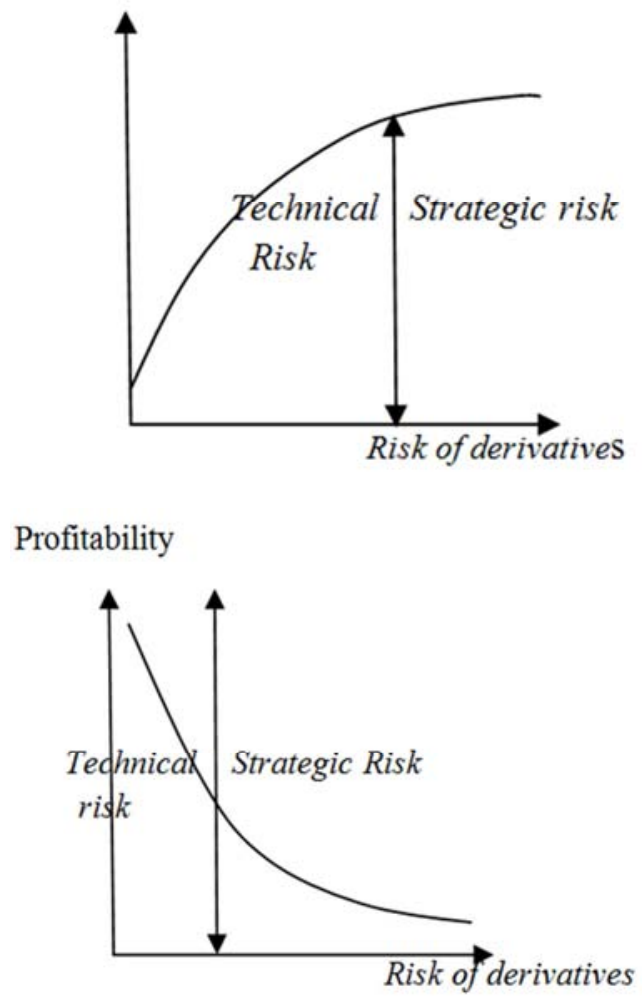

Bank Marketing (Risk versus Target)

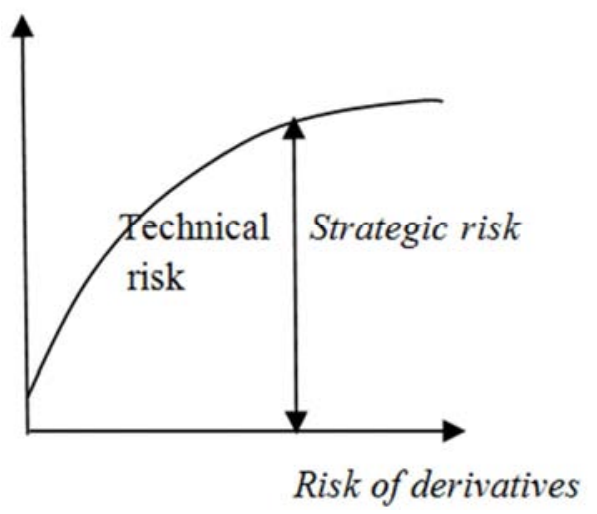

Source: the researchers

Figure 1. The derivatives and the sensitiveness towards risk. 


\subsection{Risk Inherent to Profitability}

This risk is about the contribution of dealing with derivatives to increase the net worth of the bank assets. In this vein lies the idea of the effective management of the risk (technical and organizational aspect) associated with the economic target of the bank institution (economic one). Derivatives in general must take as instruments a position which provides a reasonable attitude in the eyes of the borrowers (institutions or corporations). Indeed, profitability in its economic sense is generated and distributed along the time period of the business operation. This span is extremely exposed to different, huge and variable flow of information; here the role of derivatives is to ensure the efficient management of the information variability towards the service of the economic target (profit).

Assuming that I denotes the information, $\mathrm{P}$ the profit, then the bank wants the reach the optimum of the below system:

$P=\xi(I)$ by considering that the derivative is an endogenous variable. The efficient management of the bank is to reach a point in which:

$$
\frac{\partial I}{\partial D}=0
$$

This point means that the bank is able to monitor the information and exploit it in servicing the profit target as shown by the below exhibit:

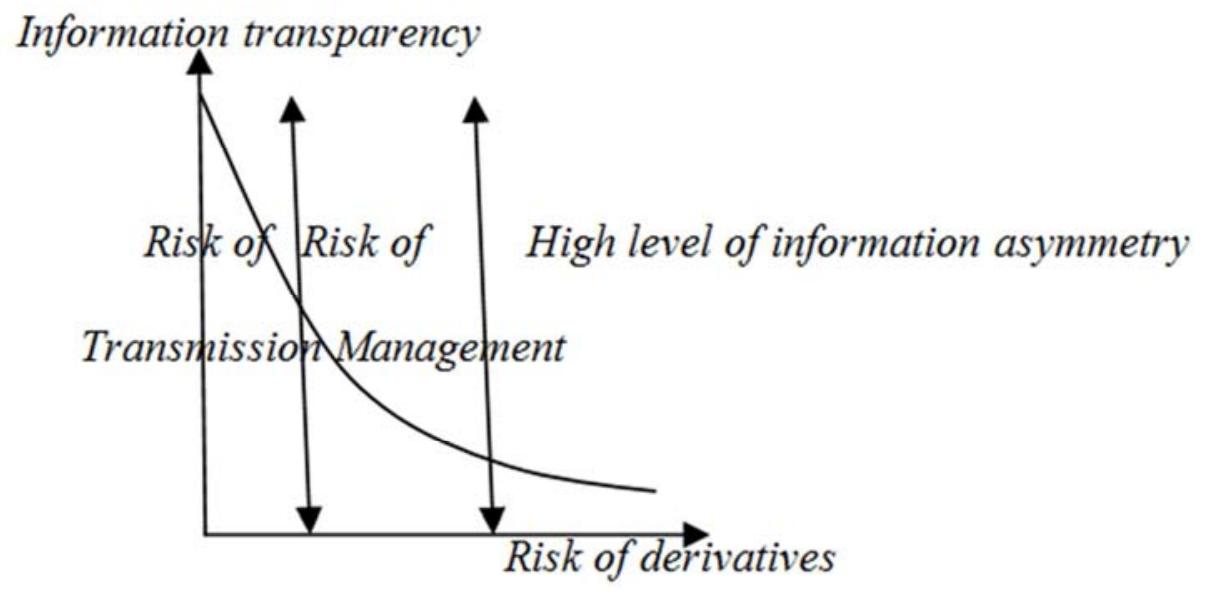

Source: the researchers

Figure 2. The derivatives and the information transparency.

\subsection{Risk Inherent to Bank Management}

Banks are economic institutions of vital role in the economy. They represent the indirect finance in which the borrower meets the lender via an intermediary. The latter accomplishes two functions: Pooling and reducing risks and it achieves two targets: Profit and high level of management. How can the derivative contribute in improving the managerial target of the bank?

The story background of the issue is that the bank behaves cautiously when it manages its assets and liabilities. The quality as well the quantity considerations of the derivative dealing are important because it is not just the quantity which influences the livelihood of the banking institution but also the quality. The latter has an obvious impact on the banking management in terms of durability and soundness. The durability means that the banks preserves and improves instantly its management techniques while soundness refers to the outstanding position of the bank in the market. Suppose that the quantity of the derivative is $Q_{y}$, the quality is $K_{y}$, the banking management has as proxy IT (level and the sophistication of the technology used, then the objective of the bank is to reduce the risk of the derivative (the risk of quantity and the quality) to increase the level of the technology used:

$$
\begin{aligned}
& p=\xi\left(Q_{y}, K_{y}\right) \\
& I T=f(D)
\end{aligned}
$$

The bank now tries to resolve the system:

$$
\begin{gathered}
\frac{\partial I T}{\partial Q_{v}}=0 \\
\frac{\partial I T}{K_{v}}=0 \\
\text { under : MiniRisk }\left(Q_{y}, K_{y}\right)
\end{gathered}
$$

\subsection{Risk Inherent to Bank Marketing}

Banks perform their function in an environment characterized by turbulence and myopia (high level of uncertainty). As any other economic entity, bank works hard to catch and maintain a respected market share. This market is constituted by different kinds of customers (borrowers, lenders, shareholders, speculators...). The strategy of the bank in this situation is to run the customers in the favor of the general objective (profit) by making a management network as it is shown by the exhibit: 

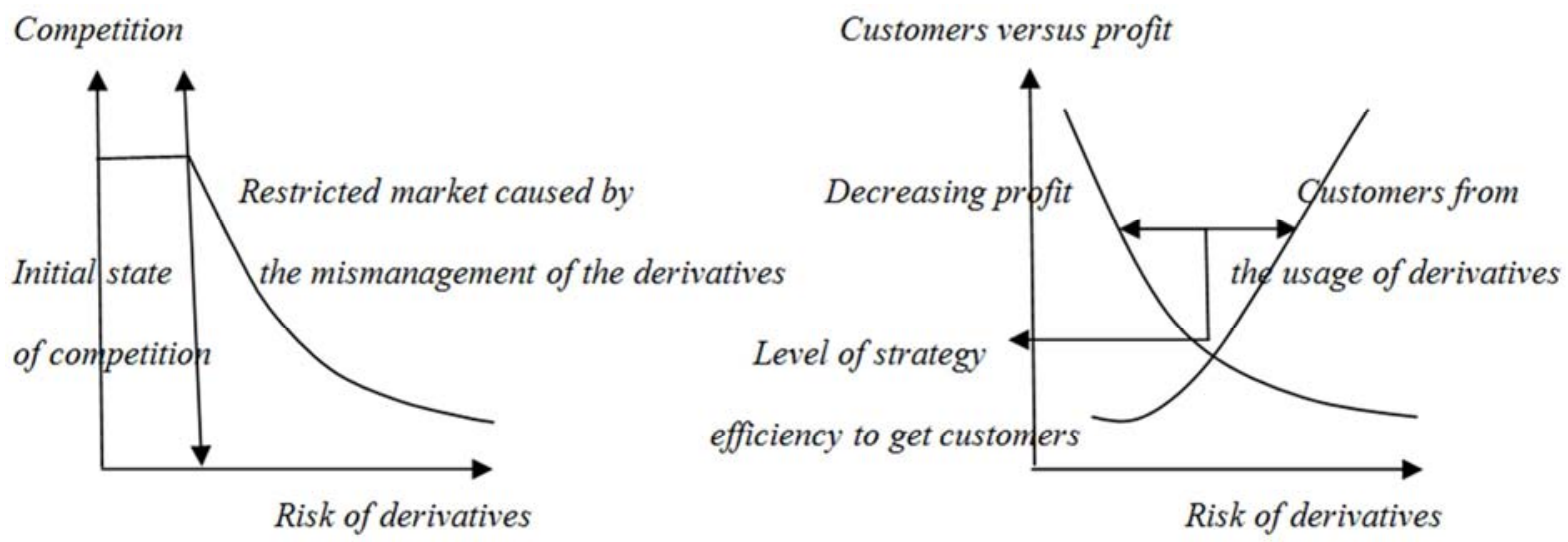

Source: the researchers

Figure 3. Competition and the derivative strategy.

Suppose that $\mathrm{M}$ is the market share of the bank measured by its customers, $\mathrm{R}$ is the risk, so the bank is intended to manage the following system:

$$
\begin{gathered}
M=\xi(D) \\
R=f(D) \\
\frac{\partial R}{\partial D}=0 \\
\frac{\partial M}{\partial D}=0
\end{gathered}
$$

\section{The Social Development of the Financial System}

The financial system is the blood of the business climate. It is nurtured by the different customers and the particularities of the environment in which the bank runs the operations. In this context, bank takes into account the determinants and the variability of the environment. The determinants are diverse: a customer, market, events, opportunities and each one of these four determinants shows a high or low rate of variability. Henceforth, it is strategically vital to analyze scrupulously the risks within each one of the determinants and their evolution. Risks of customers refer to entry and exit strategies to deal with banks: whenever the customer finds that it is not profitable for him to deal with the bank, he adopts automatically an exit strategy (shareholder for example). The market in its turn has a specific risk represented both by the price of the different financial securities and the development level of the transactions. In addition, events show an unpredictable future as they are usually the ground for harsh crises. In time of these events, the conductors of the smoothly behavior of markets vanish and the general rules of profitability, demand and supply and efficiency leave their places to the uncertainty (to forecast the future), ambiguity (to define prices) and pessimism (strong belief in the failure of the banking system. Moreover, the opportunities are to a large extent the reverse of the negative effects (favorable investment channels, level of population consumerism). The bank here is at the core of different factors:

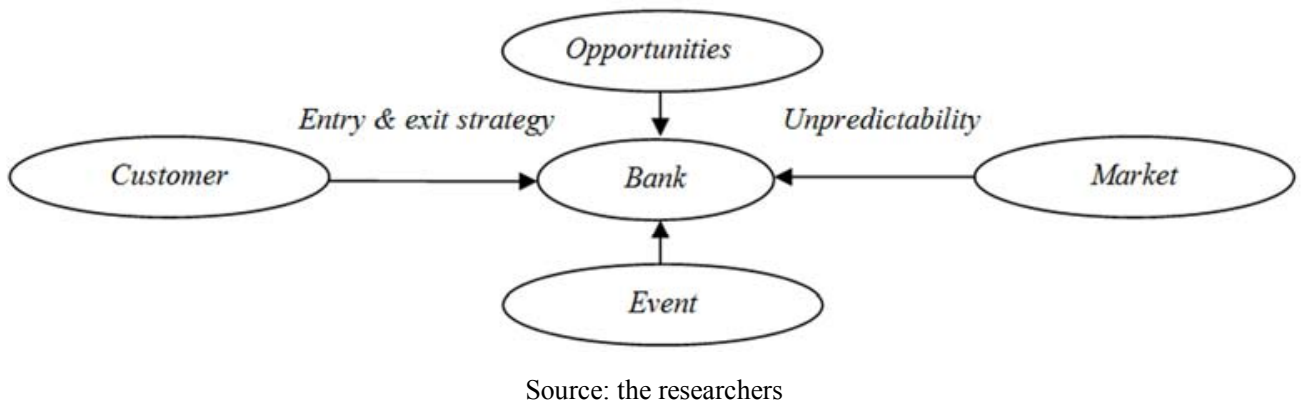

Figure 4. Banks and theenvironment interactions.

\subsection{Risk of the Entry and Exit Strategy}

Customers are economic agent rational means that they exploit the advantages and try to deal efficiently with the shortcomings. This rule is applied by the customers of the banking institution as they engage only when the opportunity is available. This availability in the scope of derivatives comes from the arbitrage between the current and the future periods. As far as there are positive correlations between the prices or revenues of the current period and the future one, 
this offers a good signal to the investor or speculator to engage in purchasing or selling a derivative and takes either an immediate or postponed benefit. This sense means implicitly that the bank monitors and analyzes the risk of the arbitrage between current and future contracts as the following:

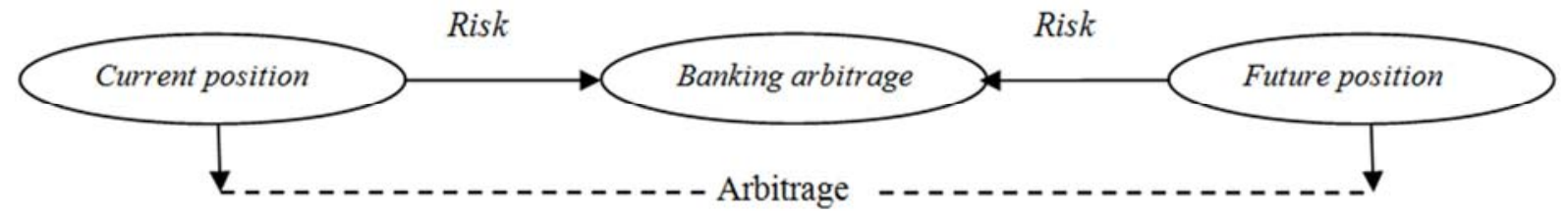

Source: the researchers

Figure 5. Derivatives and the banking arbitrage.

\subsection{Risk of Unpredictability}

The risk of unpredictability is another risk among those facing the banking institution in an attempt to create a strong position towards the derivatives. The strategy here is to adopt the derivative as a mean of signaling that forecasts and predicts the prices of different securities so the difference between the prices would be adaptable to the bank targets. Suppose that the current price of a security is $\mathrm{CP}$, therefore the strategy adopted is to resolve the following system:

$$
\begin{gathered}
R=\xi(C P, D) \\
P=f(C P, D) \\
C P=F(D) \\
\frac{\partial C P}{\partial D}=0
\end{gathered}
$$

\section{Conclusion}

This paper shows the state of correlation between the technique of the derivatives and the health of the banking system. The former could be used as a real and true instrument to improve the efficiency and the governance of the bank if the risk of dealing is well understood and managed. This process needs the clear positioning of it and the comprehension of its impacts' channels. The study paves reasonably the way for further researches about the network effect of the derivatives on the banking management both on the theoretical and empirical dimensions.

\section{References}

[1] Alibert, R. Z. (1987) 'Financial Innovation and the boundaries of banking', Managerial and Decision Economics, Vol. 8, No. 1: 67-73.

[2] Arnould, W. A., Boot and Anjan, V. T. (1997) 'Banking Scope and Financial Innovation', The Review of Financial Studies, Vol. 10, No. 4: 1099-1131.
[3] Carter. M. (1989) Financial Innovation and Financial Fragility, Journal of Economic Issues, Vol. 23, No. 3: 779793.

[4] Carlos Pérez Montes. (2014), The Effect on Competition of Banking Sector Consolidation Following the Financial Crisis of 2008, Journal of Banking and Finance 43, 124-136.

[5] Gorton. G. and Rosen, R. (1995) 'Banks and Derivatives', NBER Macroeconomics Annual, Vol. 10: 299-339.

[6] Emanuel Barnea, Yoram Landskroner, Meir Sokoler. (2015), Monetary policy and financial stability in a banking economy: Transmission mechanism and policy tradeoffs, Journal of Financial Stability 18, 78-90.

[7] Eugenio Cerutti. (2015), Drivers of cross-border banking exposures during the crisis, Journal of Banking and Finance $55,340-357$.

[8] Franziska Bremus, Marcel Fratzscher. (2015), Drivers of Structural Change in Cross-Border Banking since thje Global Financial Crisis, Journal of International Money and Finance 52, 32-59.

[9] Henry. T. C., Hu. (1989) 'Swaps, The Modern Process of Financial Innovation and the Vulnerability of a Regulatory Paradigm, University of Pennsylvania Law Review, Vol. 138, No. 2: 333-345.

[10] John V. Duca. (2015), How Capital Regulation and Other Factors drive the Role of the Shadow Banking in Funding Short Term Business Credit, Journal of Banking and Finance, $1-15$.

[11] Mardi Dungey, Jan P. A. M. Jacobs, Lestano. (2015), The Internationalization of Financial Crises: Banking and Financeial Crises 1883-2008, North American Journal of Economics and Finance 32, 29-47.

[12] Mishkin. F. S. (2004) The Economics of Money, Banking and Financial Markets, $7^{\text {th }}$ edition (The Addison-Wesley series in Economics).

[13] Shaofang Li, Matej Marinč. (2014), The use of financial derivatives and risks of U.S. bank holding companies, International Review of Financial Analysis 35, 46-71.

[14] Vincent Bouvatier, Anne-Laure Delatte. (2015), Waves of international banking integration: A tale of regional differences, European Economic Review 80, 354-373. 